\title{
Bioactive Lipidic Extracts from Octopus (Paraoctopus limaculatus): Antimutagenicity and Antiproliferative Studies
}

\section{Carolina Moreno-Félix, ${ }^{1}$ Griselda Wilson-Sánchez, ${ }^{1}$ Susana-Gabriela Cruz-Ramírez, Carlos Velázquez-Contreras, ${ }^{2}$ Maribel Plascencia-Jatomea, ${ }^{1}$ Ana Acosta, ${ }^{3}$ Lorena Machi-Lara, ${ }^{4}$ María-Lourdes Aldana-Madrid, ${ }^{1}$ Josafat-Marina Ezquerra-Brauer, ${ }^{1}$ Fernando Rocha-Alonzo, ${ }^{2}$ and Armando Burgos-Hernández ${ }^{1}$}

\footnotetext{
${ }^{1}$ Departamento de Investigación y Posgrado en Alimentos, Universidad de Sonora, Apartado Postal 1658, 83000 Hermosillo, SON, Mexico

${ }^{2}$ Departamento de Ciencias Químico-Biológicas, Universidad de Sonora, 83000 Hermosillo, SON, Mexico

${ }^{3}$ Rubio Pharma y Asociados, S.A. de C.V., Blvd. García Morales No. 330, 83210 Hermosillo, SON, Mexico

${ }^{4}$ Departamento de Investigación en Polímeros y Materiales, Universidad de Sonora, 83000 Hermosillo, SON, Mexico
}

Correspondence should be addressed to Armando Burgos-Hernández; aburgos@guayacan.uson.mx

Received 17 September 2012; Revised 4 December 2012; Accepted 5 December 2012

Academic Editor: Vernon A. Barnes

Copyright (C) 2013 Carolina Moreno-Félix et al. This is an open access article distributed under the Creative Commons Attribution License, which permits unrestricted use, distribution, and reproduction in any medium, provided the original work is properly cited.

\begin{abstract}
Fractions from an organic extract from fresh octopus (Paraoctopus limaculatus) were studied for biological activities such as antimutagenic and antiproliferative properties using Salmonella tester strains TA98 and TA100 with metabolic activation (S9) and a cancer cell line (B-cell lymphoma), respectively. A chloroform extract obtained from octopus tentacles was sequentially fractionated using thin layer chromatography (TLC), and each fraction was tested for antimutagenic and antiproliferative activities. Organic extract reduced the number of revertants caused by aflatoxin $B_{1}$ showing a dose-response type of relationship. Sequential TLC fractionation of the active extracts produced several antimutagenic and/or antiproliferative fractions. Based on the results obtained, the isolated fractions obtained from octopus contain compounds with chemoprotective properties that reduce the mutagenicity of $\mathrm{AFB}_{1}$ and proliferation of cancer cell lines.
\end{abstract}

\section{Introduction}

As food toxicology develops, more kinds of chemical mutagens and carcinogens are found to be present in foods. Many are food contaminants such as mycotoxins and pesticides, but others are present in food as a consequence of technological processes applied to them (e.g., pyrolysates, nitrosamines, polycyclic aromatic hydrocarbons, etc.) [1]. However, a great variety of compounds that are natural constituents of foods have been found to show properties that are beneficial for the consumer. Among the kinds of "functional" compounds found in food are anticholesterolemic compounds, antioxidants, antivirals, and so forth. The antimutagenic and antiproliferative agents can be considered in this group of bioactive compounds. These biologically active compounds include thiocyanates, indole-3-carbinol, allium compounds, linoleic acid, conjugated linoleic acid, polyunsaturated fatty acids, caffeic acid phenethyl ester (CAPE), and flavonoids such as pinocembrin, rutin, naringenin, and hesperetin, respectively [2].

Unsaturated fatty acids, especially the $\omega-3$ and $\omega-6$, are components of the lipid fraction of marine organisms that have been associated to the prevention of chronic degenerative diseases such as cardiovascular diseases and 
cancer [3-5]. Structurally, $\omega-3$ and $\omega-6$ fatty acids are similar to linoleic and linolenic acids, to which antimutagenicity and anticarcinogenicity have been reported $[3,6,7]$. Based on these facts, the present investigation focused on the detection of antimutagenic and antiproliferative compounds in octopus, an economically important and highly consumed seafood worldwide.

\section{Materials and Methods}

2.1. Testing Species. Octopus (Paraoctopus limaculatus) was obtained from Bahía de Kino, SON, México (approximately $2000 \mathrm{~km}$ northwest México City, México) and transported in ice to the University of Sonora Seafood Laboratory. Edible portions from octopus were separated, fresh packed, and stored at $-25^{\circ} \mathrm{C}$ until further analysis.

Octopus Extract. A $100 \mathrm{~g}$ portion of octopus muscle and 5 parts of $\mathrm{CHCl}_{3}$ were homogenized in a blender at high speed for $1 \mathrm{~min}$. Resulting mix was poured into a flask and agitated during 30 min with the aid of a Wrist Action Burrel Shaker (Burrel Corporation, Pittsburg, PA). The mix was filtered through Whatman no. 4 filter paper with vacuum, and the filtrate was evaporated to dryness under $\mathrm{N}_{2}$ stream.

2.2. Fractionation of Octopus Extract. The fractionation of octopus extract was performed according to BurgosHernandez et al. [8]. A $2.0 \mathrm{~mL}$ aliquot of octopus muscle extract was applied on to a $1.0 \mathrm{~mm}$ thick silica gel-coated preparative TLC plate and developed with chloroformacetone $(9: 1 \mathrm{v} / \mathrm{v})$. Fluorescent bands, identified with their $R_{f}$, were scrapped off the plate, and the contents of the silica were extracted with $2 \times 25 \mathrm{~mL}$ chloroform-methanolacetone $(9: 1: 1 \mathrm{v} / \mathrm{v} / \mathrm{v})$. Extract were resuspended and serially diluted in DMSO and tested for antimutagenicity and antiproliferation. When either antimutagenic or antiproliferative (or both) bands were detected, their contents were obtained again from a fresh muscle sample following the same procedure and were subjected to further fractionation (Figures 1 and 2).

2.3. Bacterial Cultures. Salmonella typhimurium TA98 and TA100 were purchased from Molecular Toxicology Inc. Fresh overnight tester strain cultures, to which DMSO was added as cryoprotective agent, and were stored at $-80^{\circ} \mathrm{C}$. Tester strains were checked routinely to confirm genetic features using the procedure described by Maron and Ames [9].

Metabolic Activation System. S9 mix (Aroclor 1254-induced, Sprague-Dawley male rat liver in $0.154 \mathrm{M} \mathrm{KCl}$ solution) was purchased from Molecular Toxicology, Inc. (Annapolis, MD, USA) and stored at $-80^{\circ} \mathrm{C}$.

2.4. Antimutagenicity Test. Dry extracts obtained either directly from octopus or from preparative-TLC fractionation of extracts were reconstituted and serially diluted with DMSO and were spiked with pure $\mathrm{AFB}_{1}$ to a final concentration of $500 \mathrm{ng}$ of $\mathrm{AFB}_{1} / 100 \mu \mathrm{L}$.
Residual mutagenicity of $\mathrm{AFB}_{1}$ was assayed using the standard plate incorporation procedure described by Maron and Ames [9]. Different $\mathrm{AFB}_{1}$ concentrations were used as a control for both tester strains. All assays were performed in triplicate.

2.5. Cell Lines. Cell lines NCTC clone L929 (normal subcutaneous connective tissue) was purchased from the American Type Culture Collection (ATCC, Rockville, MD). The M12.C3.F6 (murine B-cell lymphoma) cell line was kindly provided by Dr. Emil R. Unanue (Department of Pathology and Immunology, Washington University in St. Louis, MO). All cell cultures were cultured in Dulbecco's modified Eagle's medium (DMEM) supplemented with 5\% heat inactivated fetal calf serum and grown at $37^{\circ} \mathrm{C}$ in an atmosphere of $5 \%$ $\mathrm{CO}_{2}$.

2.6. Antiproliferation Assay. In order to evaluate the effect of octopus crude extracts and their fractions on the proliferation of different cancer cell lines, cell proliferation was determined using the standard MTT assay (3-(4,5-dimethylthiazol-2-yl)2,5-diphenyltetrazolium bromide) [10]. Briefly, 10,000 cells $(50 \mu \mathrm{L})$ were plated in each well of a flat 96 well plate. After $12 \mathrm{~h}$ incubation at $37^{\circ} \mathrm{C}$ in an atmosphere of $5 \% \mathrm{CO}_{2}$ to allow cell attachment, the cell cultures were incubated with $50 \mu \mathrm{L}$ of medium containing various concentrations of either crude extract or fraction, and the cell cultures were incubated for $48 \mathrm{~h}$. The crude extract or fraction was first resuspended in DMSO and then diluted in DMEM media. Control cell cultures were incubated with DMSO (final concentrations of DMSO $0.06 \%-0.5 \%$ ). Control cell cultures did not show any evidence of cell damage. In the last $4 \mathrm{~h}$ of the cell culture, $10 \mu \mathrm{L}$ of MTT stock solution $(5 \mathrm{mg} / \mathrm{mL})$ were added to each well [10]. Formazan crystals formed were dissolved with acidic isopropanol, and the plates were read in an ELISA plate reader (Benchmark Microplate Reader, Bio-Rad, Hercules, CA, USA), using a test wavelength of $570 \mathrm{~nm}$ and a reference wavelength of $630 \mathrm{~nm}$. Plates were normally read within $15 \mathrm{~min}$ of adding isopropanol. Data were analyzed using analysis of variance (ANOVA) with Tukey-Kramer and Duncan's multiple comparison tests (Number Cruncher Statistical Software (NCSS 2000)).

2.7. Partial Chemical/Structural Studies. In order to know about aspects of the structural characteristics of the compounds present in the bioactive fractions from octopus, instrumental studies using Fourier Transformed Infrared (FT-IR) and nuclear magnetic resonance $\left({ }^{1} \mathrm{H}-\mathrm{NMR}\right)$ were carried out to attempt to contribute to a partial chemical structural characterization. To conduct FT-IR spectroscopy, thin films of the bioactive fractions samples were elaborated on $\mathrm{ZnSe}$ cells, and spectra were obtained using a GX Perkin Elmer equipment. For NMR spectra, bioactive fractions were dissolved in $\mathrm{CDCl} 3$ and analyzed in a Bruker ADVANCE 400 spectrometer using tetramethylsilane (TMS) as a reference. For mass spectrometry, contents of the antimutagenic fraction were analyzed using a Varian 431-GC gas chromatograph equipped with a VARIAN 210-MS ion trap 
TABLE 1: Antimutagenic potential of extracts from fractions RA, RB, and RC obtained from lipidic extract of octopus (average ${ }^{\mathrm{a}}$ TA100 and TA98 revertants/plate, with S9).

\begin{tabular}{|c|c|c|c|c|}
\hline \multirow{2}{*}{ Extract fraction $^{c}$} & \multicolumn{4}{|c|}{ Fraction dilution $^{\mathrm{c}}$} \\
\hline & $1 \times 10^{0}$ & $1 \times 10^{-1}$ & $1 \times 10^{-2}$ & $1 \times 10^{-3}$ \\
\hline \multicolumn{5}{|l|}{ TA98 } \\
\hline $\mathrm{RA}\left(R_{f}=0.0-0.29\right)$ & $170 \pm 13$ & $296 \pm 24$ & $267 \pm 13$ & $333 \pm 18$ \\
\hline $\mathrm{RB}\left(R_{f}=0.29-0.69\right)$ & $117 \pm 10$ & $271 \pm 18$ & $338 \pm 27$ & $350 \pm 31$ \\
\hline $\mathrm{RC}\left(R_{f}=0.69-1.0\right)$ & $215 \pm 7$ & $387 \pm 23$ & $299 \pm 21$ & $453 \pm 33$ \\
\hline \multicolumn{5}{|l|}{ TA100 } \\
\hline $\mathrm{RA}\left(R_{f}=0.0-0.29\right)$ & $71 \pm 16$ & $203 \pm 12$ & $567 \pm 35$ & $621 \pm 53$ \\
\hline $\mathrm{RB}\left(R_{f}=0.29-0.69\right)$ & $127 \pm 3$ & $361 \pm 39$ & $534 \pm 37$ & $567 \pm 24$ \\
\hline $\mathrm{RC}\left(R_{f}=0.69-1.0\right)$ & $185 \pm 15$ & $565 \pm 43$ & $523 \pm 48$ & $536 \pm 30$ \\
\hline
\end{tabular}

mass detector. Chromatographic separation was achieved using a capillary column CP-SIL 43CB $(25 \mathrm{~m} \times 0.32 \mathrm{~mm}$ $\times 0.2 \mu \mathrm{m})$ from VARIAN and an ultrahigh purity helium as carrier gas at a constant flow of $13 \mathrm{~mL} / \mathrm{min}$, in splitless injection mode. Three $\mu \mathrm{L}$ of underivatized and derivatized with $\mathrm{BF} 3 /$ methanol sample were injected. An initial oven temperature of $120^{\circ} \mathrm{C}$ was held for $5 \mathrm{~min}$, followed by a ramp of $10^{\circ} \mathrm{C} / \mathrm{min}$ to $180^{\circ} \mathrm{C}$, holding for $30 \mathrm{~min}$, followed by a ramp of $10^{\circ} \mathrm{C} / \mathrm{min}$ to $210^{\circ} \mathrm{C}$, holding for $20 \mathrm{~min}$. The injection port temperature was maintained at $250^{\circ} \mathrm{C}$. Total chromatographic separation was achieved in $64 \mathrm{~min}$. The ion trap detector was set as follows. The transfer line, manifold, and trap temperatures were 205,80 , and $150^{\circ} \mathrm{C}$, respectively. All mass spectra were acquired in the electron impact mode. Ionization was maintained off during the first $2 \mathrm{~min}$, to avoid solvent overloading. The mass range was $40-500 \mathrm{~m} / \mathrm{z}$, with a scan rate of $1 \mathrm{scan} / \mathrm{s}$.

\section{Results}

3.1. Antimutagenicity. Octopus muscle was extracted and fractionated using TLC, and the fractions obtained (Figure 1) were tested for antimutagenicity. RA, RB, and RC fractions were obtained after the first TLC procedure (TLC 1). Antimutagenicity testing showed all extracts to have an inhibitory effect on the mutagenicity of $500 \mathrm{ng}$ of $\mathrm{AFB}_{1}$ for both tester strains (Table 1) suggesting the presence of antimutagenic compounds in all of them; however, a welldefined dose-response type of relationship was observed for fraction $\mathrm{RB}$, and it was selected for further fractionation since it was the fraction that achieved the greater inhibition ( $>76 \%$ for both tester strains) of the mutagenicity of induced by $500 \mathrm{ng} \mathrm{AFB}_{1}$. After second TLC isolation procedure, materials present in RB separated into 2 fractions (Figure 1). Fraction RB2 decreased the reversion rate achieved by $500 \mathrm{ng}$ $\mathrm{AFB}_{1}(>75 \%$ for TA100 and $>90 \%$ for TA98) suggesting that antimutagenic compounds were contained in this fraction (Table 2). Although other fractions also decreased reversion caused by $\mathrm{AFB}_{1}$, dose-response type of relationships was not as consistent in both tester strains as that observed for RB2. Therefore, RB2 was selected for further fractionation. After a third TLC isolation, procedure 3 fractions were obtained from RB2 (Figure 1). Antimutagenicity results showed that fraction RB21 differed from the rest since it effectively inhibited the mutagenicity of $\mathrm{AFB}_{1}$ induced in both tester strains (Table 3). RB21, which inhibited the mutagenic potential of $\mathrm{AFB}_{1}$ in more than $95 \%$ and $89 \%$ for TA98 and TA100 tester strains, respectively, was selected for further fractionation. Fractionation of RB21 (TLC 4) resulted into three regions, RB211, RB212, and RB213. Antimutagenesis testing revealed that fraction RB213 more ( $>66 \%$ of mutagenicity inhibition for both tester strains) efficiently decreased tester strains reversion rate than RB211 and RB212 (both $<40 \%$ for both TA98 and TA100), showing a dose-response relationship with a lower slope (Table 4).

Therefore, RB213 was selected and fractionated by means of a TLC 5 procedure. Development of TLC 5 showed that most of the materials migrated to the top half portion of the plate. This allowed the determination of 3 fractions that were named RB2131 (no materials observed), RB2132, and RB2133; therefore, only de 2 top fractions were assayed.

The antimutagenicity assay performed showed RB2132 as the fraction that inhibited the mutagenicity of $\mathrm{AFB}_{1}$ in more than $84 \%$ for both tester strains (Table 5), whereas RB2133 inhibitory activity was no higher than 40\%; therefore, RB2132 contents were fractionated using a sixth TLC procedure. TLC 6 applied to RB2132 resulted in only 2 bands, RB21321 and RB21322. The contents form these bands were extracted and tested for antimutagenicity. Results from this assay showed that both bands contained compounds that inhibited the mutagenicity of $\mathrm{AFB}_{1}$ in a dose-response type of relationship (Table 6). RB21321 inhibited more than $70 \%$ the mutagenicity of $\mathrm{AFB}_{1}$ in both tester strains, whereas RB21322 exhibited an inhibition activity higher than 55\% for both TA98 and TA100 tester strains. The contents from both bands were subjected for further TLC procedures using different solvent system without successful fractionation. 
TABLE 2: Anti-mutagenic potential of $\mathrm{AFB}_{1}{ }^{\mathrm{a}}$-spiked fractions obtained from thin layer chromatography fractionation of fraction $\mathrm{RB}\left(R_{f}=\right.$ 0.18-0.78) from TLC 1 (average ${ }^{\mathrm{b}}$ TA100 and TA98 revertants/plate, with S9).

\begin{tabular}{|c|c|c|c|c|}
\hline \multirow{2}{*}{ Extract fraction ${ }^{c}$} & \multicolumn{4}{|c|}{ Fraction dilution $^{c}$} \\
\hline & $1 \times 10^{0}$ & $1 \times 10^{-1}$ & $1 \times 10^{-2}$ & $1 \times 10^{-3}$ \\
\hline \multicolumn{5}{|l|}{ TA98 } \\
\hline $\mathrm{RB} 1\left(R_{f}=0.18-0.78\right)$ & $464 \pm 98$ & $1230 \pm 64$ & $933 \pm 59$ & $1023 \pm 53$ \\
\hline $\mathrm{RB} 2\left(R_{f}=0.78-1.00\right)$ & $82 \pm 13$ & $548 \pm 48$ & $632 \pm 56$ & $955 \pm 65$ \\
\hline \multicolumn{5}{|l|}{ TA100 } \\
\hline $\mathrm{RB} 1\left(R_{f}=0.18-0.78\right)$ & $564 \pm 37$ & $1355 \pm 94$ & $1299 \pm 105$ & $1283 \pm 88$ \\
\hline $\operatorname{RB} 2\left(R_{f}=0.78-1.00\right)$ & $315 \pm 20$ & $348 \pm 25$ & $668 \pm 32$ & $740 \pm 13$ \\
\hline
\end{tabular}

$\mathrm{AFB}_{1}$ (used as positive control) tested at 500 and $1000 \mathrm{ng} /$ plate induced $1073 \pm 29$ and $1841 \pm 102$ and $1229 \pm 37$ and $2286 \pm 103$ revertants/plate for TA98 and TA100, respectively. Spontaneous revertants were $52 \pm 4$ and $160 \pm 4$ for TA98 and TA100, respectively.

${ }^{\mathrm{b}}$ Values are means of three replicates \pm SEM.

${ }^{c}$ Extracts were diluted and spiked with enough toxin to yield $500 \mathrm{ng}$ of pure $\mathrm{AFB}_{1} / \mathrm{plate}$.

TABLE 3: Anti-mutagenic potential of $\mathrm{AFB}_{1}{ }^{\mathrm{a}}$-spiked fractions obtained from thin layer chromatography fractionation of fraction $\mathrm{RB} 2\left(R_{f}=\right.$ 0.78-1.00) from TLC 2 (average ${ }^{\mathrm{b}}$ TA100 and TA98 revertants/plate, with S9).

\begin{tabular}{|c|c|c|c|c|}
\hline \multirow{2}{*}{ Extract fraction $^{c}$} & \multicolumn{4}{|c|}{ Fraction dilution $^{c}$} \\
\hline & $1 \times 10^{0}$ & $1 \times 10^{-1}$ & $1 \times 10^{-2}$ & $1 \times 10^{-3}$ \\
\hline \multicolumn{5}{|l|}{ TA98 } \\
\hline $\mathrm{RB} 21\left(R_{f}=0.00-0.47\right)$ & $49 \pm 9$ & $73 \pm 4$ & $257 \pm 20$ & $325 \pm 24$ \\
\hline $\operatorname{RB} 22\left(R_{f}=0.47-0.79\right)$ & $71 \pm 3$ & $141 \pm 20$ & $219 \pm 19$ & $218 \pm 28$ \\
\hline $\operatorname{RB} 23\left(R_{f}=0.79-1.00\right)$ & $18 \pm 2$ & $175 \pm 13$ & $236 \pm 18$ & $265 \pm 21$ \\
\hline \multicolumn{5}{|l|}{ TA100 } \\
\hline $\operatorname{RB} 21\left(R_{f}=0.00-0.47\right)$ & $175 \pm 30$ & $198 \pm 18$ & $220 \pm 15$ & $275 \pm 71$ \\
\hline $\operatorname{RB} 22\left(R_{f}=0.47-0.79\right)$ & $292 \pm 12$ & $455 \pm 31$ & $843 \pm 27$ & $883 \pm 12$ \\
\hline $\operatorname{RB} 23\left(R_{f}=0.79-1.00\right)$ & $320 \pm 25$ & $695 \pm 40$ & $567 \pm 44$ & $1687 \pm 70$ \\
\hline
\end{tabular}

$\mathrm{AFB}_{1}$ (used as positive control) tested at $500 \mathrm{ng} /$ plate induced $1006 \pm 83$ and $1689 \pm 78$ revertants/plate for TA98 and TA100, respectively. Spontaneous revertants were $55 \pm 3$ and $188 \pm 14$ for TA98 and TA100, respectively.

${ }^{\mathrm{b}}$ Values are means of three replicates \pm SEM.

${ }^{c}$ Extracts were diluted and spiked with enough toxin to yield $500 \mathrm{ng}$ of pure $\mathrm{AFB}_{1}$ plate.

TABLE 4: Anti-mutagenic potential of $\mathrm{AFB}_{1}{ }^{\mathrm{a}}$-spiked fractions obtained from thin layer chromatography fractionation of fraction $\mathrm{RB} 21\left(R_{f}=\right.$ 0.78-1.00) from TLC 2 (average ${ }^{\mathrm{b}}$ TA100 and TA98 revertants/plate, with S9).

\begin{tabular}{|c|c|c|c|c|}
\hline \multirow{2}{*}{ Extract fraction $^{c}$} & \multicolumn{4}{|c|}{ Fraction dilution $^{c}$} \\
\hline & $1 \times 10^{0}$ & $1 \times 10^{-1}$ & $1 \times 10^{-2}$ & $1 \times 10^{-3}$ \\
\hline \multicolumn{5}{|l|}{ TA98 } \\
\hline $\mathrm{RB} 211\left(R_{f}=0.00-0.22\right)$ & $628 \pm 49$ & $576 \pm 43$ & $499 \pm 55$ & $549 \pm 34$ \\
\hline $\mathrm{RB} 212\left(R_{f}=0.22-0.68\right)$ & $371 \pm 13$ & $345 \pm 25$ & $489 \pm 29$ & $650 \pm 68$ \\
\hline $\operatorname{RB} 213\left(R_{f}=0.68-1.00\right)$ & $199 \pm 15$ & $335 \pm 23$ & $401 \pm 28$ & $576 \pm 21$ \\
\hline \multicolumn{5}{|l|}{ TA100 } \\
\hline $\mathrm{RB} 211\left(R_{f}=0.00-0.22\right)$ & $1549 \pm 89$ & $1466 \pm 123$ & $1657 \pm 220$ & $1425 \pm 124$ \\
\hline $\mathrm{RB} 212\left(R_{f}=0.22-0.68\right)$ & $1006 \pm 93$ & $941 \pm 45$ & $1178 \pm 129$ & $918 \pm 28$ \\
\hline $\mathrm{RB} 213\left(R_{f}=0.68-1.00\right)$ & $499 \pm 35$ & $829 \pm 63$ & $1237 \pm 128$ & $1465 \pm 121$ \\
\hline
\end{tabular}

${ }^{\mathrm{a}} \mathrm{AFB}_{1}$ (used as positive control) tested at $500 \mathrm{ng} /$ plate induced $605 \pm 33$ and $1689 \pm 78$ revertants/plate for TA98 and TA100, respectively. Spontaneous revertants were $55 \pm 3$ and $188 \pm 14$ for TA98 and TA100, respectively.

${ }^{\mathrm{b}}$ Values are means of three replicates \pm SEM.

${ }^{c}$ Extracts were diluted and spiked with enough toxin to yield $500 \mathrm{ng}$ of pure $\mathrm{AFB}_{1} /$ plate. 


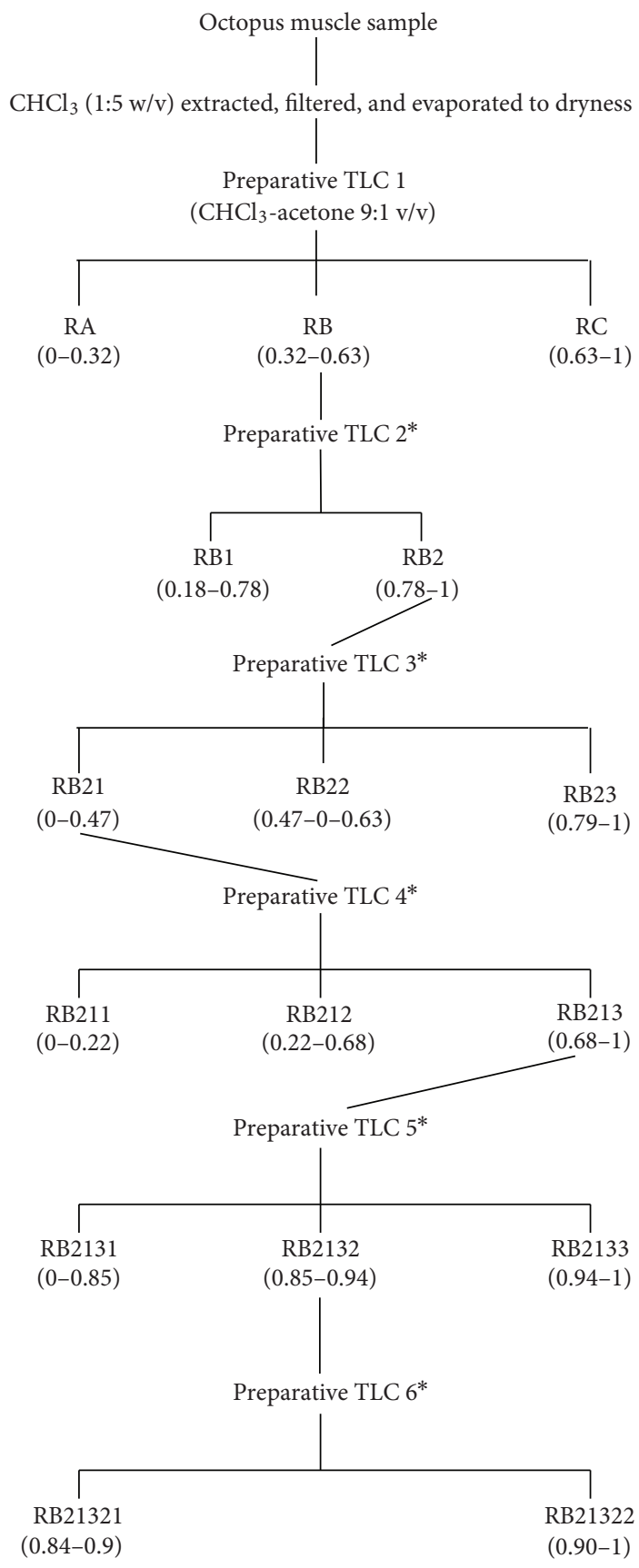

FIGURE 1: Schematic for separation and isolation of antimutagenic fractions from octopus. Numbers in parenthesis are $R_{f}$ values. ${ }^{*}$ TLC procedure conditions were identical to TLC1.

3.2. Antiproliferation Activity. In order to investigate the presence of antiproliferative agents in octopus lipidic extract, a fractionation procedure parallel to that carried out for antimutagens was performed (Figure 2). The fractions RA, $\mathrm{RB}$, and $\mathrm{RC}$ obtained from the first TLC fractionation were tested on the antiproliferative assays. All octopus fractions showed antiproliferative activity on the murine cancer cell line M12.C3.F6 (B-cell lymphoma) in a concentrationdependent manner (Figure 3). However, only fractions RA and $\mathrm{RC}$ were able to inhibit the cellular proliferation beyond
$50 \%$, at the lowest doses tested $(12.5$ and $25 \mu \mathrm{g} / \mathrm{mL})$. The highest level of cellular proliferation inhibition was observed for fraction RC (about 90\% for the second lowest dose tested $(25 \mu \mathrm{g} / \mathrm{mL})$; therefore, RC was selected for further fractionation.

From the second TLC fractionation step, fractions RC1 and RC2 were obtained (Figure 2) and tested for antiproliferation activity (Figure 3). Fractions RC1 and RC2 were able to inhibit cellular proliferation in more than $50 \%$ at the highest dose tested $(100 \mu \mathrm{g} / \mathrm{mL})$. However, more than $60 \%$ cellular 


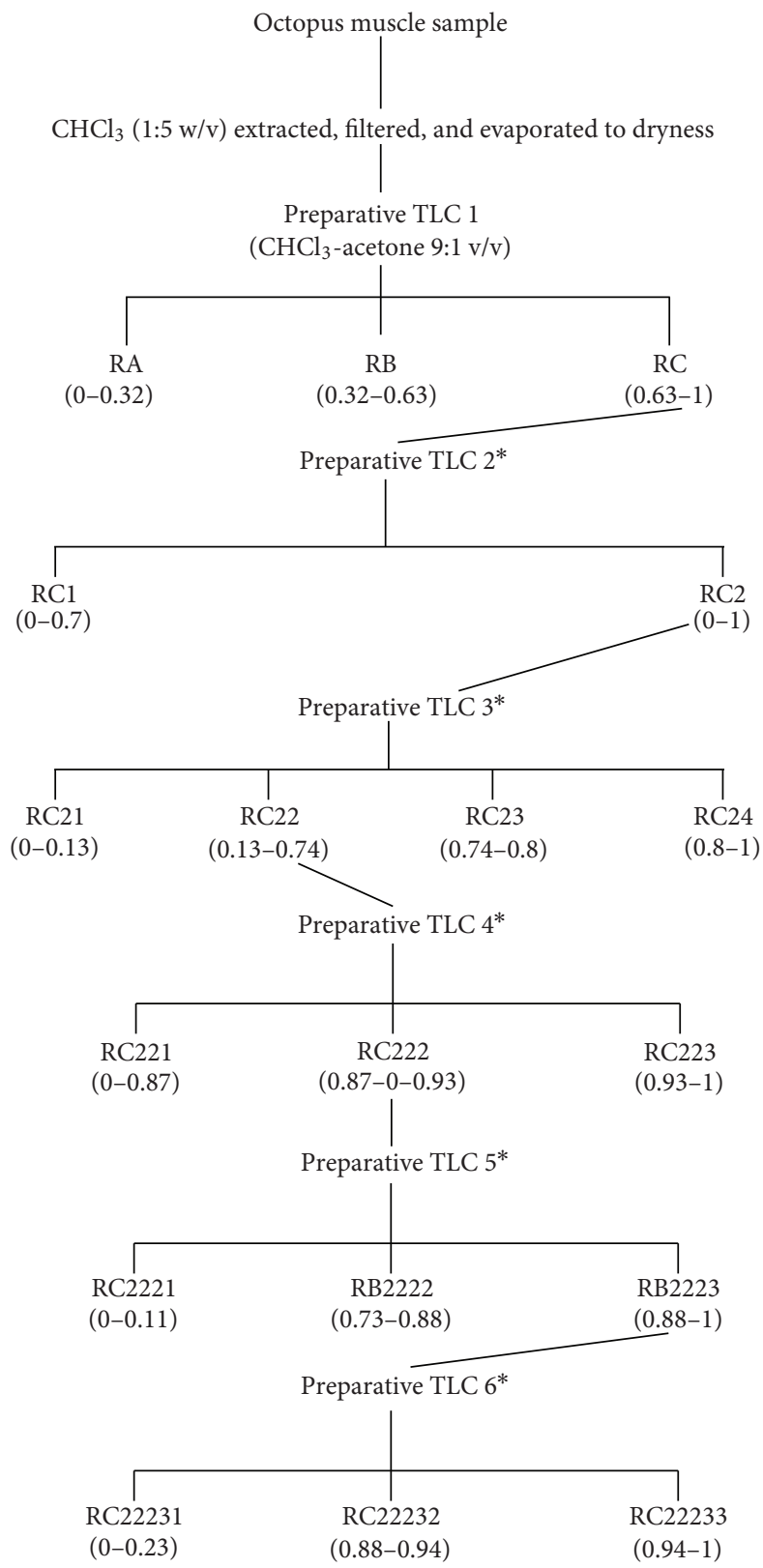

Figure 2: Schematic for separation and isolation of antiproliferative fractions from octopus. Numbers in parenthesis are $R_{f}$ values. ${ }^{*}$ TLC procedure conditions were identical to TLC1.

proliferation inhibition was observed in cancer cell cultures exposed to fraction RC2; therefore, this fraction was selected to continue with the fractionation process.

Figures 4(a)-4(d) show the antiproliferative activities of octopus fractions obtained from subsequent TLC fractionation (TLC 3, TLC 4, TLC 5, and TLC 6) of fraction RC2. All fractions derived from RC2 had significant inhibitory effect on the growth of the cancer cell line tested. In contrast, $\mathrm{RC} 2$-derived fractions showed a much lower antiproliferative effect on the murine noncancerous cell line L-929 than on the cancer cell line M12.C3.F6 (Figures 4(e)-4(h)).

3.3. Partial Chemical/Structural Studies. In order to obtain information about the presence of functional groups and structural aspects to the materials detected in the bioactive (both, antimutagenic fraction RB21321 and antiproliferative fraction RC22233) isolated fractions from octopus, FT-IR and ${ }^{1} \mathrm{H}-\mathrm{NMR}$ analyses were performed. NMR (Figure 5) studies showed broad peaks visualized in the $1.3 \mathrm{ppm}$ region; these signals were attributed to methylene protons, probably from long chain fatty acids, such as those present in $\omega$ 3 fatty acids. Additional contributions obtained from lipid resonances (0.9-1.7 ppm region) are also present. In this, the wide peak at $0.9 \mathrm{ppm}$ region was associated to methyl groups [11]. Results from FT-IR (Figure 6) carried out on bioactive fractions from octopus provided of a spectra that coincided in a typical signal for carbonyl function group; the peaks visualized in the 1600-1680 range could be related to 
TABLE 5: Anti-mutagenic potential of $\mathrm{AFB}_{1}{ }^{\mathrm{a}}$-spiked fractions obtained from thin layer chromatography fractionation of fraction RB213 $\left(R_{f}\right.$ $=0.68-1.00$ ) from TLC 2 (average ${ }^{\mathrm{b}}$ TA100 and TA98 revertants/plate, with S9).

\begin{tabular}{|c|c|c|c|c|}
\hline \multirow{2}{*}{ Extract fraction $^{c}$} & \multicolumn{4}{|c|}{ Fraction dilution $^{c}$} \\
\hline & $1 \times 10^{0}$ & $1 \times 10^{-1}$ & $1 \times 10^{-2}$ & $1 \times 10^{-3}$ \\
\hline \multicolumn{5}{|l|}{ TA98 } \\
\hline $\mathrm{RB} 2132\left(R_{f}=0.85-0.94\right)$ & $79 \pm 11$ & $245 \pm 25$ & $409 \pm 29$ & $502 \pm 28$ \\
\hline $\mathrm{RB} 2133\left(R_{f}=0.94-1.00\right)$ & $399 \pm 35$ & $435 \pm 49$ & $489 \pm 41$ & $576 \pm 21$ \\
\hline \multicolumn{5}{|l|}{ TA100 } \\
\hline $\mathrm{RB} 2132\left(R_{f}=0.85-0.94\right)$ & $178 \pm 13$ & $389 \pm 41$ & $603 \pm 59$ & $918 \pm 28$ \\
\hline $\mathrm{RB} 2133\left(R_{f}=0.94-1.00\right)$ & $499 \pm 35$ & $829 \pm 63$ & $1237 \pm 128$ & $1465 \pm 121$ \\
\hline
\end{tabular}

TABLE 6: Anti-mutagenic potential of $\mathrm{AFB}_{1}{ }^{\mathrm{a}}$-spiked fractions obtained from thin layer chromatography fractionation of fraction $\mathrm{RB} 2132\left(R_{f}\right.$ $=0.68-1.00$ ) from TLC 2 (average ${ }^{\mathrm{b}}$ TA100 and TA98 revertants/plate, with S9).

\begin{tabular}{|c|c|c|c|c|}
\hline \multirow{2}{*}{ Extract fraction $^{c}$} & \multicolumn{4}{|c|}{ Fraction dilution $^{c}$} \\
\hline & $1 \times 10^{0}$ & $1 \times 10^{-1}$ & $1 \times 10^{-2}$ & $1 \times 10^{-3}$ \\
\hline \multicolumn{5}{|l|}{ TA98 } \\
\hline $\mathrm{RB} 21321\left(R_{f}=0.84-0.90\right)$ & $169 \pm 11$ & $263 \pm 17$ & $461 \pm 29$ & $534 \pm 48$ \\
\hline $\mathrm{RB} 21322\left(R_{f}=0.90-1.00\right)$ & $150 \pm 14$ & $301 \pm 29$ & $423 \pm 38$ & $401 \pm 45$ \\
\hline \multicolumn{5}{|l|}{ TA100 } \\
\hline $\mathrm{RB} 21321\left(R_{f}=0.84-0.90\right)$ & $278 \pm 23$ & $492 \pm 41$ & $603 \pm 59$ & $918 \pm 28$ \\
\hline $\mathrm{RB} 21322\left(R_{f}=0.90-1.00\right)$ & $423 \pm 39$ & $734 \pm 52$ & $847 \pm 78$ & $907 \pm 37$ \\
\hline
\end{tabular}

the unsaturated hydrocarbons featuring $\mathrm{C}=\mathrm{C}$, with attached hydrogens. The $\mathrm{C}-\mathrm{H}$ stretch vibrations at $2900 \mathrm{~cm}^{-1}$ may be attributed to methylene groups; this agrees with results from NMR which suggest the presence of fatty acids. However, the signals observed in the aromatic region (7.5-7.8 ppm) of the ${ }^{1} \mathrm{H}-\mathrm{NMR}$ spectra suggest the possibility of the presence of an aromatic type of compound or a compound with a cyclic portion in its structure.

Antimutagenic fraction RB21321 was analyzed by mass spectrometry. Mass spectrum (Figure 7) shows 29 peaks with retention times ranging from 7 to $61 \mathrm{~min}$. Most of these peaks showed retention times shorter than $20 \mathrm{~min}$. When the contents of the antimutagenic fraction were derivatized with $\mathrm{BF} 3 /$ methanol, 5 additional peaks were observed within this interval, which correspond to methylated long-chain fatty acids. This confirms the results obtained from the RMN and FT-IR analyses. Even though the antimutagenic fraction analyzed is still a mixture of several compounds (possibly saturated and unsaturated fatty acids), more than $70 \%$ of the fraction consists of only 5 different compounds. This is in accordance with the signs obtained by NMR results. However, further investigation is necessary to conduct for a full structural characterization.

\section{Discussion}

Previous research performed in our laboratory allowed us to detect the existence of compounds in yellowtail fish (Seriola lalandi), lisa fish (Mugil cephalus), and cazon fish (Mustelus lunulatus) [8], as well as in shrimps [12] that have the capability to inhibit the mutagenicity of aflatoxin $B_{1}$ in the Ames test. Many substances found in the marine environment have been associated to a number of biological properties. Omega3 polyunsaturated fatty acids ( $\omega$-3PUFAs) have been implicated in chemoprevention of cancer $[5,13,14]$. Omega-3 PUFAs also have been related to the suppression of cancerous tumors $[15,16]$ and to reduced risk for prostate cancer [17, 18]. Therefore, the present research work intended to isolate compound(s) from the lipidic fraction of octopus that would have antimutagenic and/or antiproliferative properties. All of the fractions obtained right after the first fractionation procedure were capable to inhibit the induction of bacterial reversion, showing a dose-response type of relationship in both tester strains, suggesting the presence of antimutagens in every fraction. All of the fractions were able to cause an inhibition of $\mathrm{AFB}_{1}$ mutagenicity close to $50 \%$, even at the highest dilution tested. At this point, we could have selected any of the fractions to continue with the isolation 


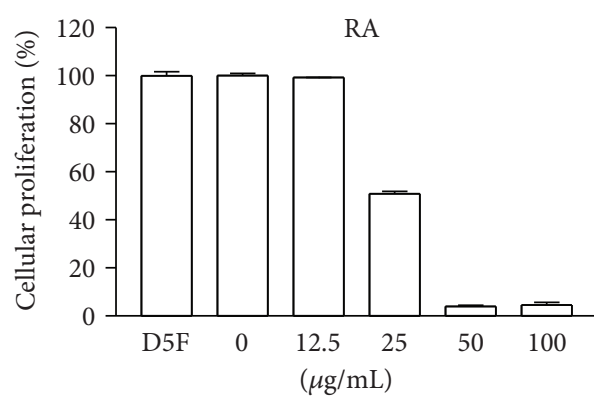

(a)

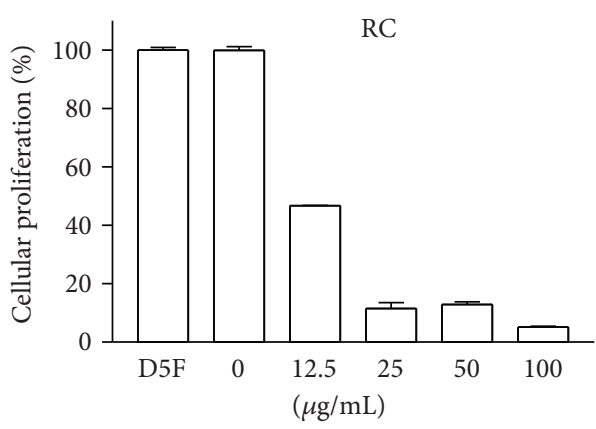

(c)

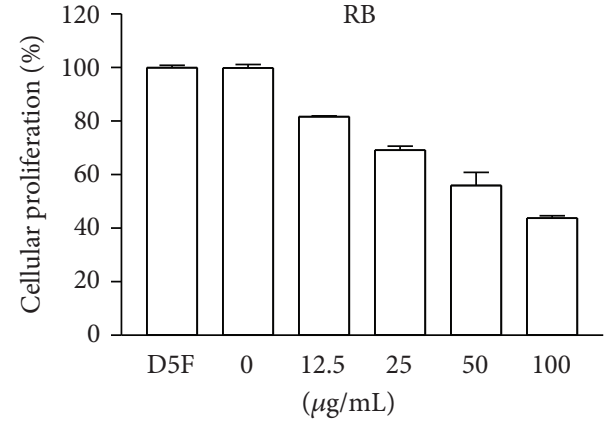

(b)

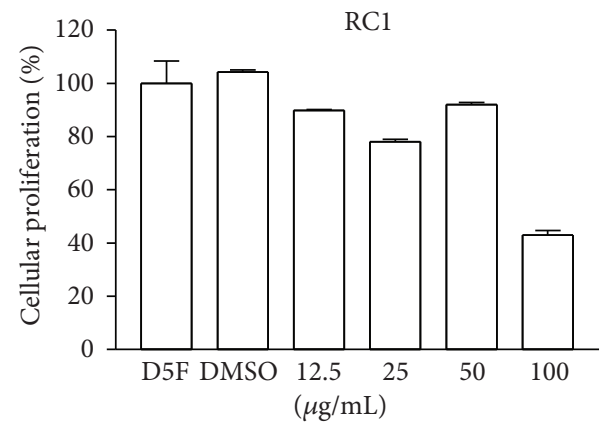

(d)

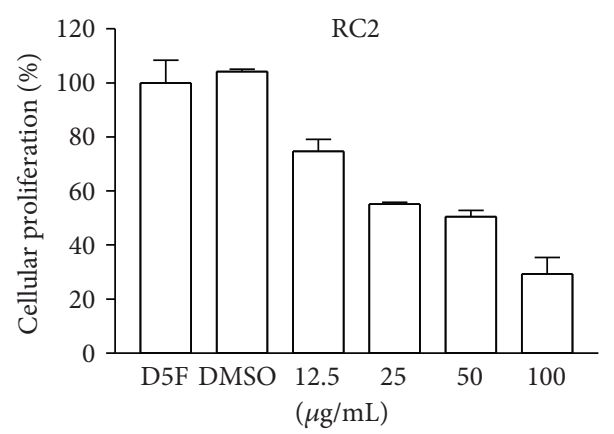

(e)

FIGURE 3: Antiproliferative effect of lipid extracts from octopus on murine cancerous cell lines. Murine cancer M12.C3.F6 cell lines were treated with different dose lipidic extracts during $48 \mathrm{~h}$. Cellular proliferation was determined by standard MTT assay (3-(4,5-dimethylthiazol2-yl)-2,5-diphenytetrazolium bromide). The results shown are representative from at least three independent experiments. All values represent mean of triplicate determination \pm standard deviation. Significant differences $(P \leq 0.05)$ from control cell cultures are marked with an asterisk. Control cell cultures were incubated with DMSO (0.5\%).

process. However, for both strains, the lowest reversion rate was observed for fraction RB, suggesting that contents from this fraction might have a higher potency in inhibiting the mutagenicity of $\mathrm{AFB}_{1}$; therefore, $\mathrm{RB}$ was selected for further fractionation.

Additional studies on the antimutagenic properties of fractions RA and RC are undergoing.

Fraction $\mathrm{RB}$ was fractionated into 2 groups of bands coded as RB1 and RB2 (Figure 1). Antimutagenesis testing performed to the extracts from these fractions (Table 2) showed that fraction RB2 had the most consistent doseresponse type of relationship in both tester strains. RB1 partially inhibited the mutagenicity of $\mathrm{AFB}_{1}$ towards both tester strains; however, it failed to show a dose-response type of relationship. However, these results may suggest the presence of antimutagenic compounds which are minor components of fraction RB or have less antimutagenic potency than those contained in fractions RB2. Based on the dose-response relationship and antimutagenic potency, fraction RB2 was selected for further fractionation.

Fraction RB2 was separated into 3 bands which were also tested for antimutagenicity (Table 3 ). From the three extracts obtained and tested, fraction RB21 caused the highest inhibition of $\mathrm{AFB}_{1}$ mutagenicity showing a doseresponse type of relationship and lowering the reversion rate at the spontaneous reversion when was undiluted. Fractions RB22 and RB23 showed antimutagenicity when undiluted; however, this activity was lost more rapidly upon 


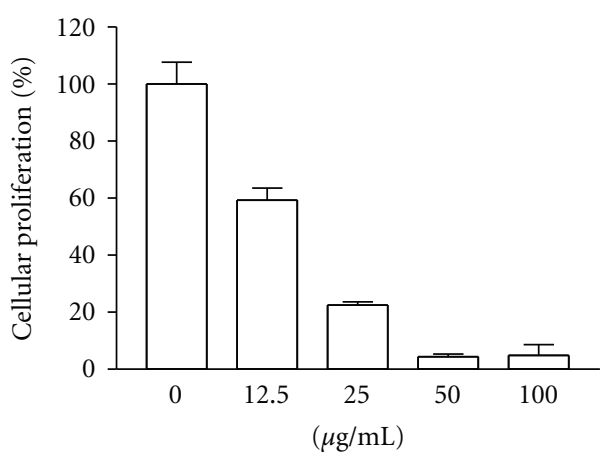

(a)

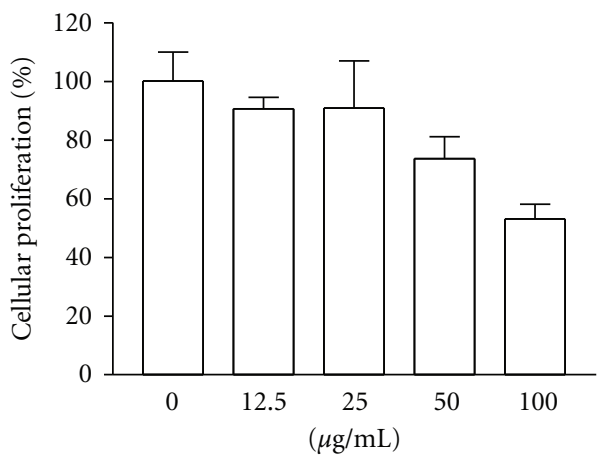

(c)

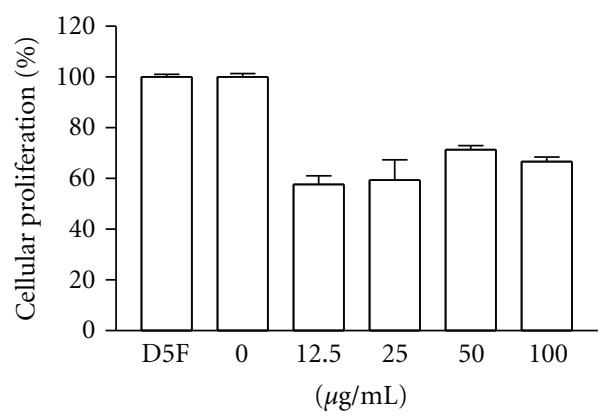

(e)

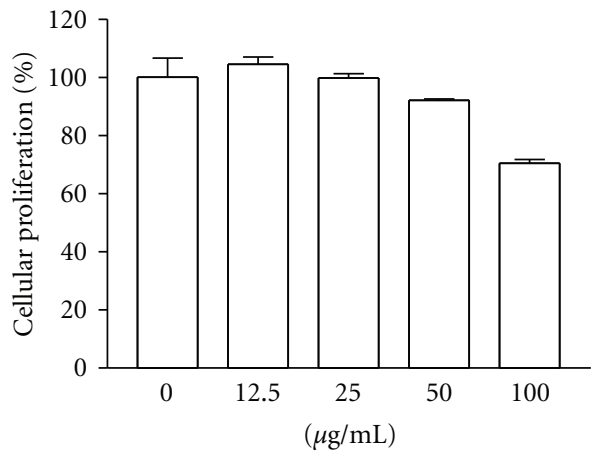

(g)

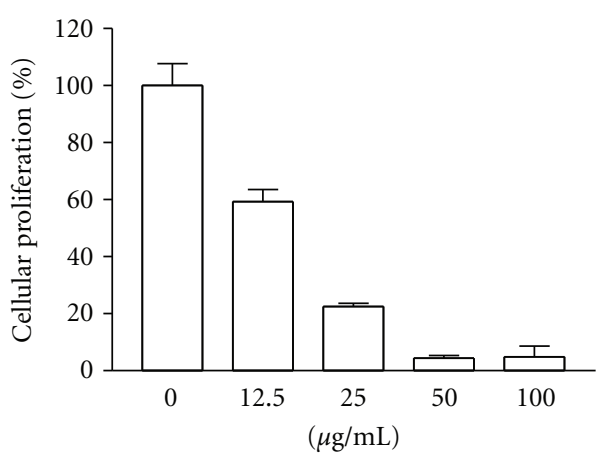

(b)

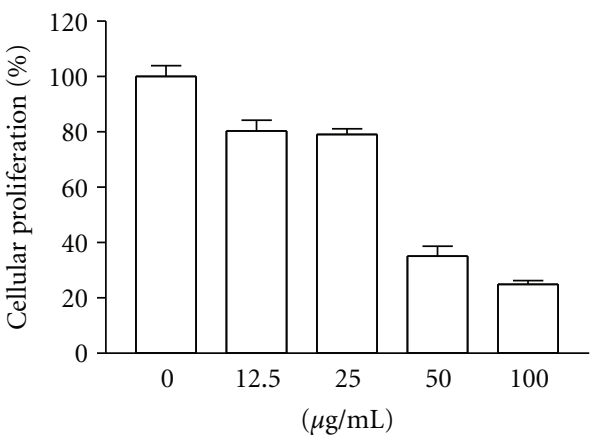

(d)

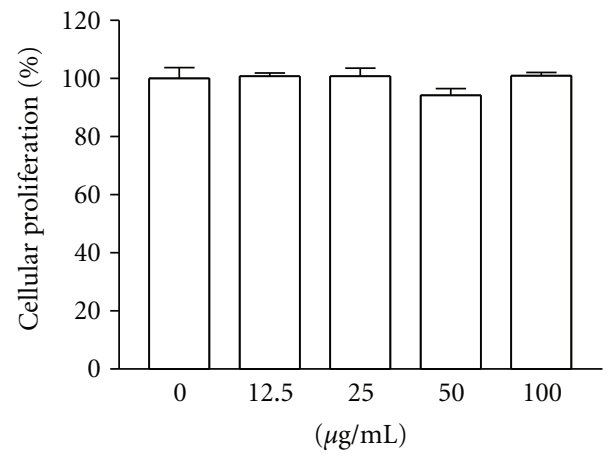

(f)

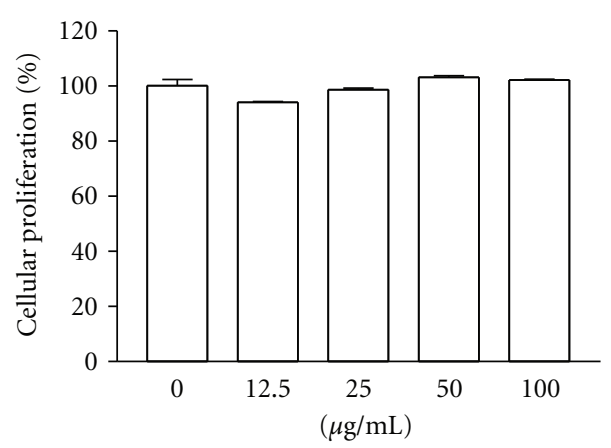

(h)

FIGURE 4: Antiproliferative effect of lipid extracts from octopus on murine cancerous and noncancerous cell lines. Murine cancer M12.C3.F6 (a)-(d) and noncancerous (e)-(h) cell lines were treated with different dose lipidic extracts during $48 \mathrm{~h}$. The results shown are representative from at least three independent experiments. All values represent mean of triplicate determination \pm standard deviation. Significant differences $(P \leq 0.05)$ from control cell cultures are marked with an asterisk. Control cell cultures were incubated with DMSO $(0.5 \%)$. 


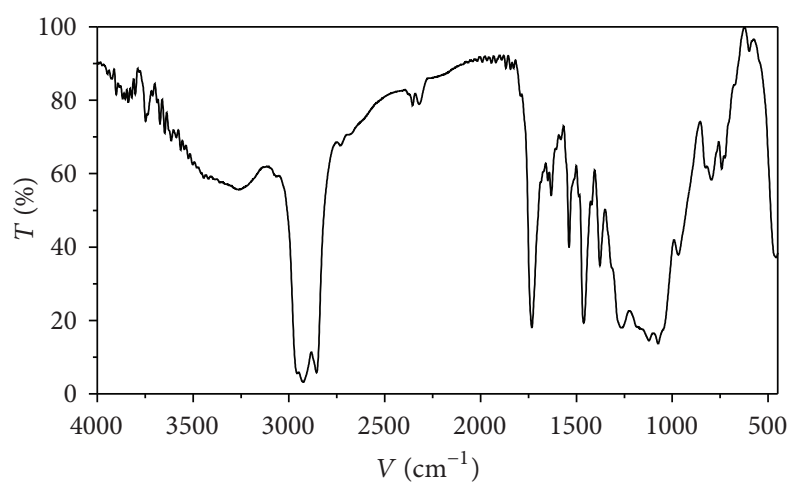

(a)

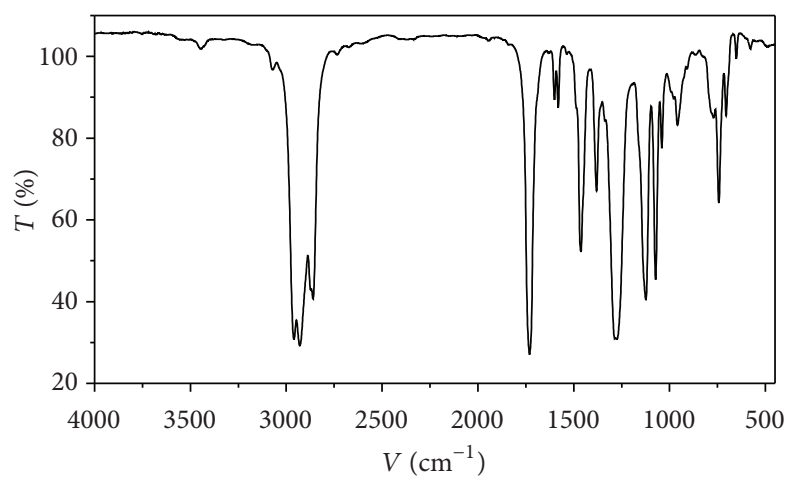

(b)

FIGURE 5: FT-IR spectra of antimutagenic fraction RB21321 (a) and antiproliferative fraction RC22233 (b), both obtained from a lipidic extract from octopus.

first dilution. A possible reason for this apparent loss of antimutagenicity after the third step in the fractionation process is the possible existence of synergistic antimutagenic compounds that may lose their antimutagenic properties when are separate. However, the possible loss of material throughout the fractionation process is not discounted. Based on the aforementioned, the fractionation of RB21 proceeded. The contents of RB21 fractionated into three regions on the TLC plate: RB211, RB212, and RB213. Results from the antimutagenicity assay showed that RB212 inhibited $\mathrm{AFB}_{1}$ in a greater extent than the other two fractions. These results suggested that antimutagenic compounds were concentrated in this fraction located in the middle portion of the TLC plate. The contents of this fraction were extracted and subjected to a fifth TLC procedure in order to continue with the isolation of antimutagenic compounds from octopus. After TLC 5, materials contained in fraction RB213 migrated to the top portion of the plate. In order to facilitate the extraction of the materials, the plate was divided into 3 fractions, RB2131 (no materials observed), RB2132, and RB213. Although both fractions RB2132 and RB213 showed antimutagenic potential, contents from RB2132 inhibited $\mathrm{AFB}_{1}$ mutagenicity in both tester strains showing a consistent dose-response type of relationship. The sixth TLC procedure applied to RB2132 resulted in two other fractions, RB21321 and RB21322. Contents from both fractions were

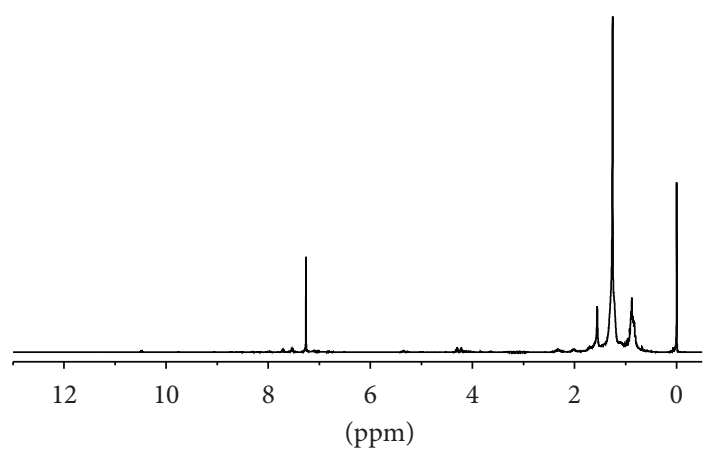

(a)

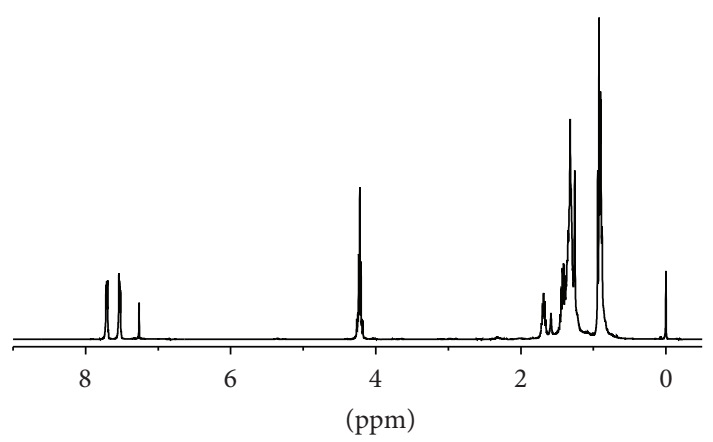

(b)

Figure 6: ${ }^{1} \mathrm{H}-\mathrm{RMN}$ spectra (CDCl3/TMS) of antiproliferative fraction RC22233 (a) and antimutagenic fraction RB21321 (b), both obtained from a lipidic extract from octopus.

localized in the upper portion of the plate, showing their affinity for the solvent used $\left(\mathrm{CHCl}_{3}\right.$-acetone $\left.9: 1\right)$. Both were antimutagenic showing similar dose-response relationships, which suggest the presence of at least 2 compounds with similar antimutagenic characteristics. Attempts to fraction both RB21321 and RB21322 using different solvents system were unsuccessful, suggesting that the chemical nature of the compounds contained in both fractions is similar. Further studies on the chemical/structural characterization of RB21321 and RB21322 are under way.

As mentioned before, three regions (RA, RB, and RC) were obtained from the fractionation of the lipidic extract from octopus. Fraction RB was the most antimutagenic fraction; however, all fractions showed antiproliferative activity, being RA and RC the fractions that had the highest inhibition of cancer cell proliferation (Figure 3). These results suggest that all three fractions contained both antimutagens and antiproliferative compounds; however, this investigation focused on the search for the compounds with the most potent activities. Fractions RA and RC inhibited murine cancer cell proliferation in a dose-dependent manner; however, at the lowest dose tested $(12.5 \mu \mathrm{g} / \mathrm{mL})$, fraction RC inhibited more than $50 \%$ of cell proliferation compared to the control. Therefore, $\mathrm{RC}$ was considered the most potent antiproliferative fraction, and it was selected for further fractionation.

Two fractions are derived from fraction RC (RC1 and $\mathrm{RC} 2$ ). RC2, at a dose of $100 \mu \mathrm{g} / \mathrm{mL}$, inhibited more than $60 \%$ 


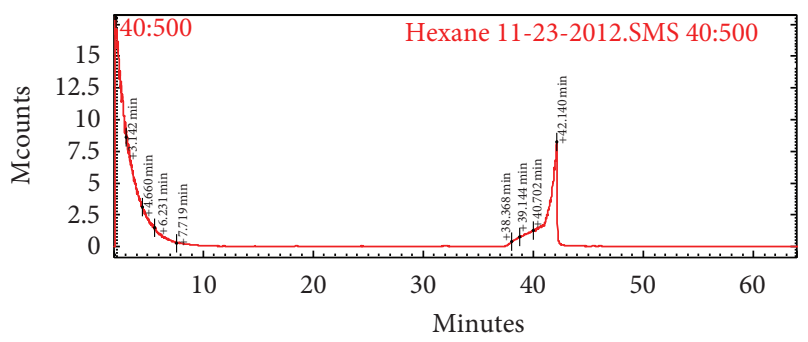

(a)

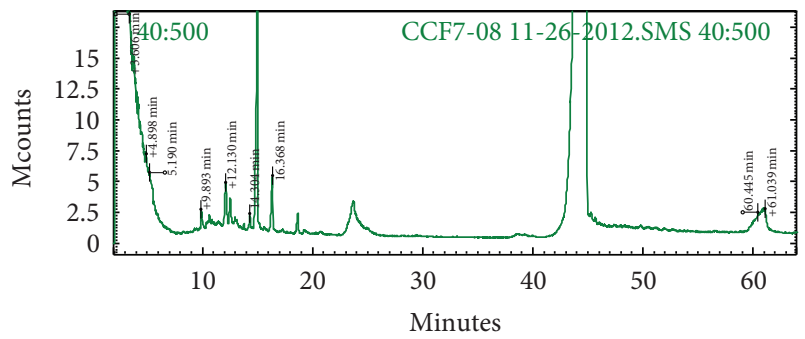

(b)

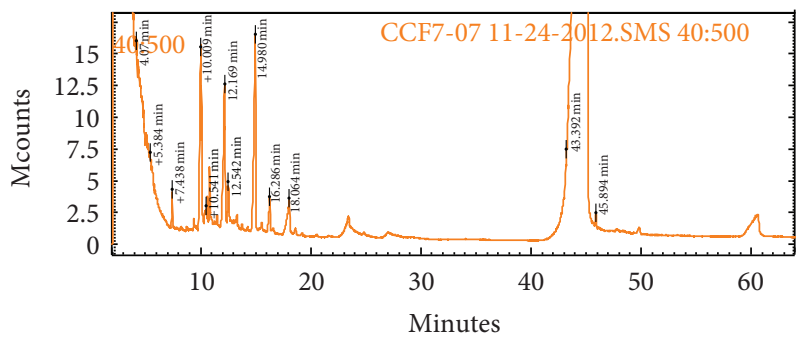

(c)

FIGURE 7: GC-MS spectra of underivatized (b) and derivatized antimutagenic fraction RB21321 (c) obtained from the lipidic fraction of octopus. Samples were solubilized in hexane (a).

of cell proliferation compared to the control (Figure 3). These results suggest that antiproliferative compounds of fraction $\mathrm{RC}$ were partitioned to fraction RC2; therefore, this fraction was subjected to additional TLC procedures.

From the third TLC fractionation step, three fractions (RC21, RC22, and RC23) were obtained from fraction RC2; fraction RC22 showed the highest inhibition of cancer cell proliferation (close to 90\%). This might suggest that components with this type of biological activity were isolated into this fraction and possibly separated from other interfering compounds. Along with the fractionation procedure (similar to that followed to isolate antimutagenic compounds), several fractions were obtained from which the presence of antiproliferative compounds was evident (Figure 4). These lipidic compounds present in those fractions from octopus substantially delayed the growth of the murine cancer cell M12.C3.F6, but the growth of normal murine cell line L929 was considerably less affected. These observations suggest that active constituents of octopus have preferential antiproliferative effects on cancer cell lines.

\section{Conclusion}

Further studies need to be performed for a full chemical and biological characterization of the preferential effect of octopus fractions on murine cancer cell lines. Results from this study suggest that within various compounds in the lipid fraction of octopus, a group of saturated and unsaturated fatty acids are responsible for the bioactivity against either the mutagenicity of $\mathrm{AFB}_{1}$ or murine cancerous cell proliferation, or against both. Although n-3PUFAs may be considered as factors partially responsible for the bioactivities observed in the first fractions obtained in this study, the isolation and identification of the actual antimutagenic and antiproliferative compounds in octopus are the focus of our ongoing research.

\section{Authors' Contribution}

C. Velázquez-Contreras and A. Burgos-Hernández contributed equally to this research work.

\section{Acknowledgment}

The authors wish to thank CONACyT for financing Grant no. 107012 and graduate scholarship granted to C. Moreno-Félix, G. Wilson-Sánchez, and S.-G. Cruz-Ramírez.

\section{References}

[1] K. Watanabe, T. Ohta, and Y. Shirasu, "Antimutagenic effects of benzaldehyde and its derivatives on mutagenesis induced by 4-Nitroquinoline-1-oxide in Escherichia coli," Agricultural and Biological Chemistry, vol. 52, pp. 1041-1045, 1988.

[2] J. Hernandez, F. M. Goycoolea, J. Quintero et al., "Sonoran propolis: chemical composition and antiproliferative activity on cancer cell lines," Planta Medica, vol. 73, no. 14, pp. 1469-1474, 2007.

[3] H. W. Renner and H. Delincee, "Different antimutagenic actions of linoleic- and linolenic acid derivatives on busulfan-induced genotoxicity in Chinese hamsters," Nutrition Research, vol. 8, no. 6, pp. 635-642, 1988.

[4] K. L. Fritsche and P. V. Johnston, "Effect of dietary $\alpha$-linolenic acid on growth, metastasis, fatty acid profile and prostaglandin production of two murine mammary adenocarcinomas," Journal of Nutrition, vol. 120, no. 12, pp. 1601-1609, 1990.

[5] D. P. Rose and J. M. Connolly, "Omega-3 fatty acids as cancer chemopreventive agents," Pharmacology and Therapeutics, vol. 83 , no. 3, pp. 217-244, 1999.

[6] A. Burgos-Hernández, R. López-García, H. Njapau, and D. L. Park, "Anti-mutagenic compounds from corn," Food Additives and Contaminants, vol. 18, no. 9, pp. 797-809, 2001.

[7] A. Burgos-Hernández, R. López-García, H. Njapau, and D. L. Park, "Partial chemical/structural elucidation of anti-mutagenic compounds from corn," Toxicology, vol. 166, no. 3, pp. 161-170, 2001.

[8] A. Burgos-Hernandez, M. Peña-Sarmiento, and F. MorenoOchoa, "Mutagencity and antimutagencity studies of lipidic extracts from yellowtail fish (Seriola lalandi), lisa fish (Mugil cephalus) and cazón fish (Mustelus lunulatus)," Food and Chemical Toxicology, vol. 40, no. 10, pp. 1469-1474, 2002. 
[9] D. M. Maron and B. N. Ames, "Revised methods for the Salmonella mutagenicity test," Mutation Research, vol. 113, no. 3-4, pp. 173-215, 1983.

[10] T. Mosmann, "Rapid colorimetric assay for cellular growth and survival: application to proliferation and cytotoxicity assays," Journal of Immunological Methods, vol. 65, no. 1-2, pp. 55-63, 1983.

[11] R. Sacchi, I. Medina, S. P. Aubourg, F. Addeo, and L. Paolillo, "Proton nuclear magnetic resonance rapid and structurespecific determination of $\omega-3$ polyunsaturated fatty acids in fish lipids," Journal of the American Oil Chemists' Society, vol. 70, no. 3, pp. 225-228, 1993.

[12] G. Wilson-Sanchez, C. Moreno-Félix, C. Velazquez et al., "Antimutagenicity and antiproliferative studies of lipidic extracts from white shrimp (Litopenaeus vannamei)," Marine Drugs, vol. 8, no. 11, pp. 2795-2809, 2010.

[13] Y. Ito, H. Shimizu, T. Yoshimura et al., "Serum concentrations of carotenoids, $\alpha$-tocopherol, fatty acids, and lipid peroxides among Japanese in Japan, and Japanese and Caucasians in the US," International Journal for Vitamin and Nutrition Research, vol. 69, no. 6, pp. 385-395, 1999.

[14] A. P. Simopoulos, "Evolutionary aspects of omega-3 fatty acids in the food supply," Prostaglandins Leukotrienes and Essential Fatty Acids, vol. 60, no. 5-6, pp. 421-429, 1999.

[15] C. P. Burns, S. Halabi, G. H. Clamon et al., "Phase I clinical study of fish oil fatty acid capsules for patients with cancer cachexia: cancer and leukemia group B study 9473," Clinical Cancer Research, vol. 5, no. 12, pp. 3942-3947, 1999.

[16] D. P. Rose and J. M. Connolly, "Antiangiogenicity of docosahexaenoic acid and its role in the suppression of breast cancer cell growth in nude mice," International Journal of Oncology, vol. 15, no. 5, pp. 1011-1015, 1999.

[17] A. E. Norrish, C. M. Skeaff, G. L. B. Arribas, S. J. Sharpe, and R. T. Jackson, "Prostate cancer risk and consumption of fish oils: a dietary biomarker-based case-control study," British Journal of Cancer, vol. 81, no. 7, pp. 1238-1242, 1999.

[18] Y. J. Yang, S. H. Lee, S. J. Hong, and B. C. Chung, "Comparison of fatty acid profiles in the serum of patients with prostate cancer and benign prostatic hyperplasia," Clinical Biochemistry, vol. 32, no. 6, pp. 405-409, 1999. 


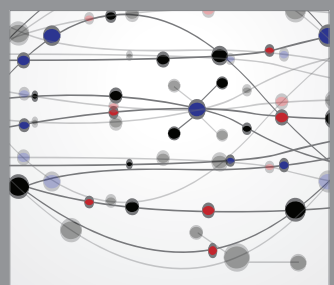

The Scientific World Journal
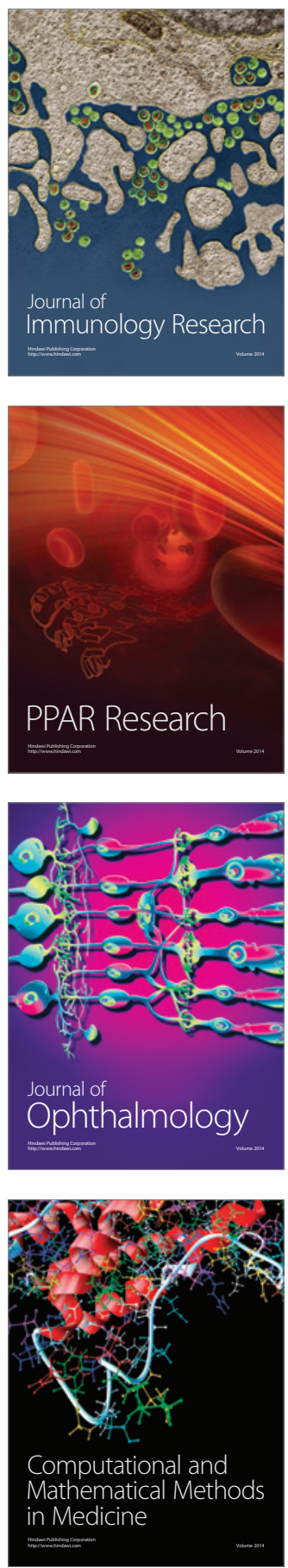

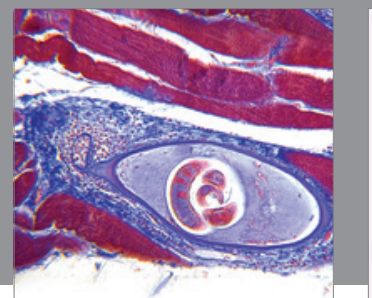

Gastroenterology

Research and Practice
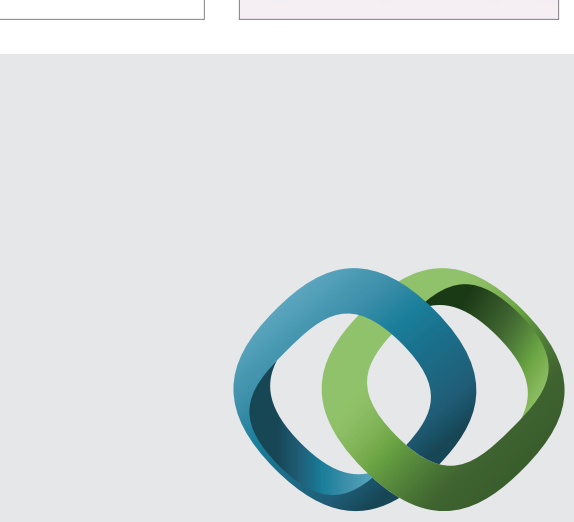

\section{Hindawi}

Submit your manuscripts at

http://www.hindawi.com
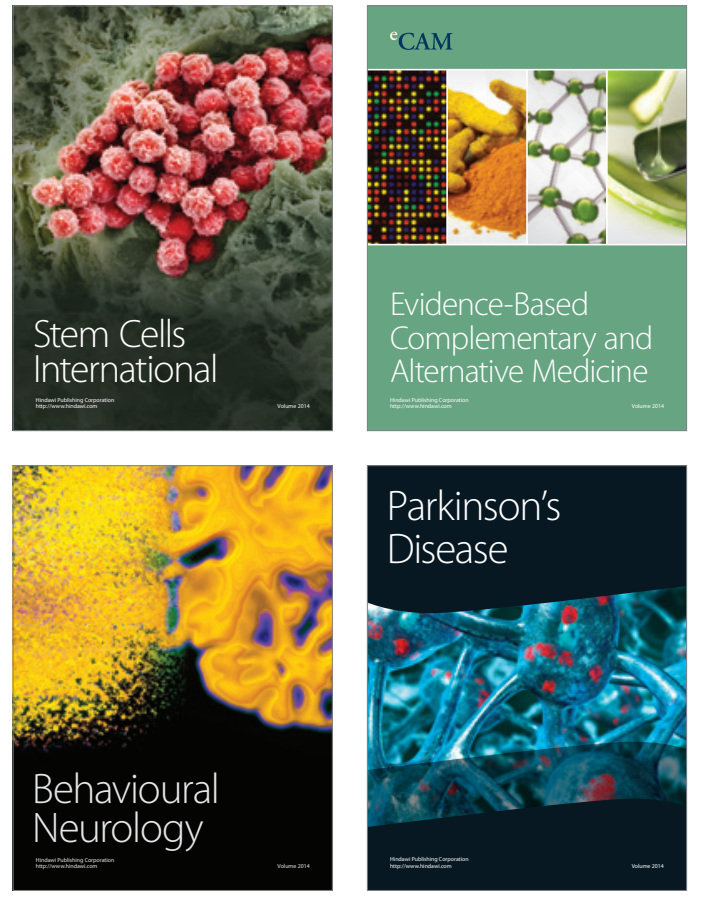
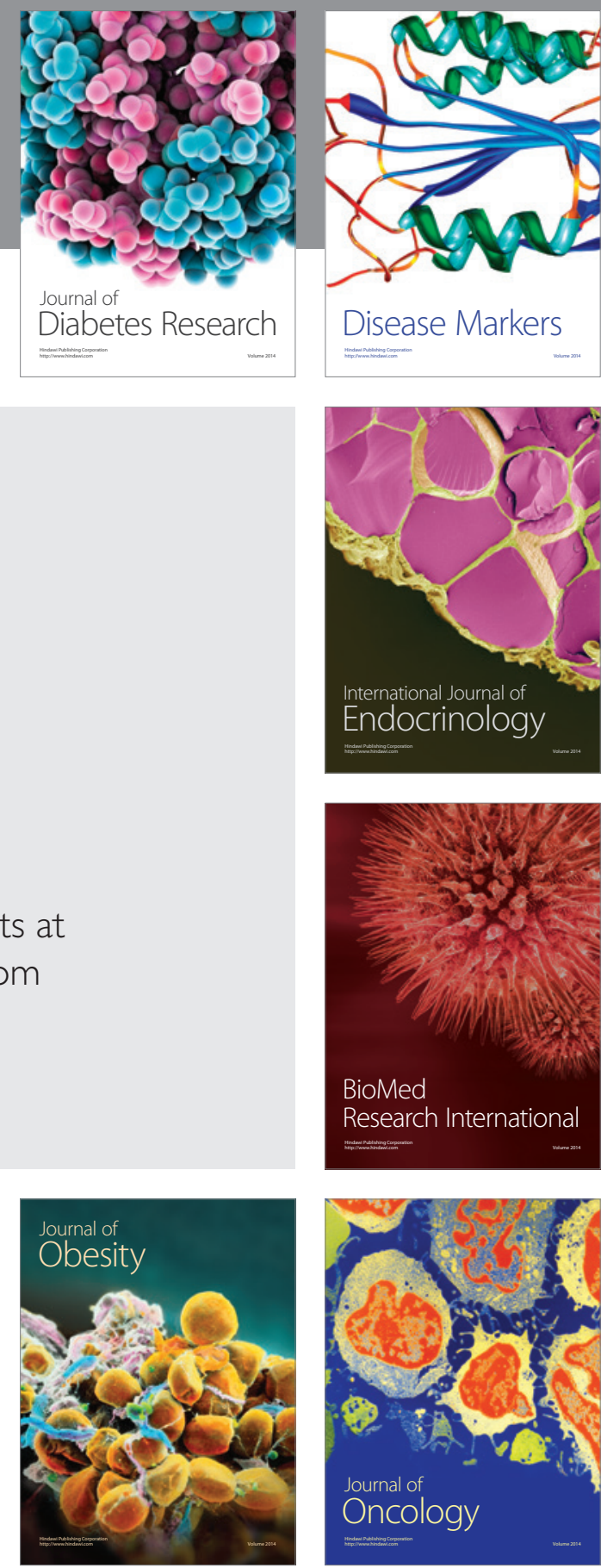

Disease Markers
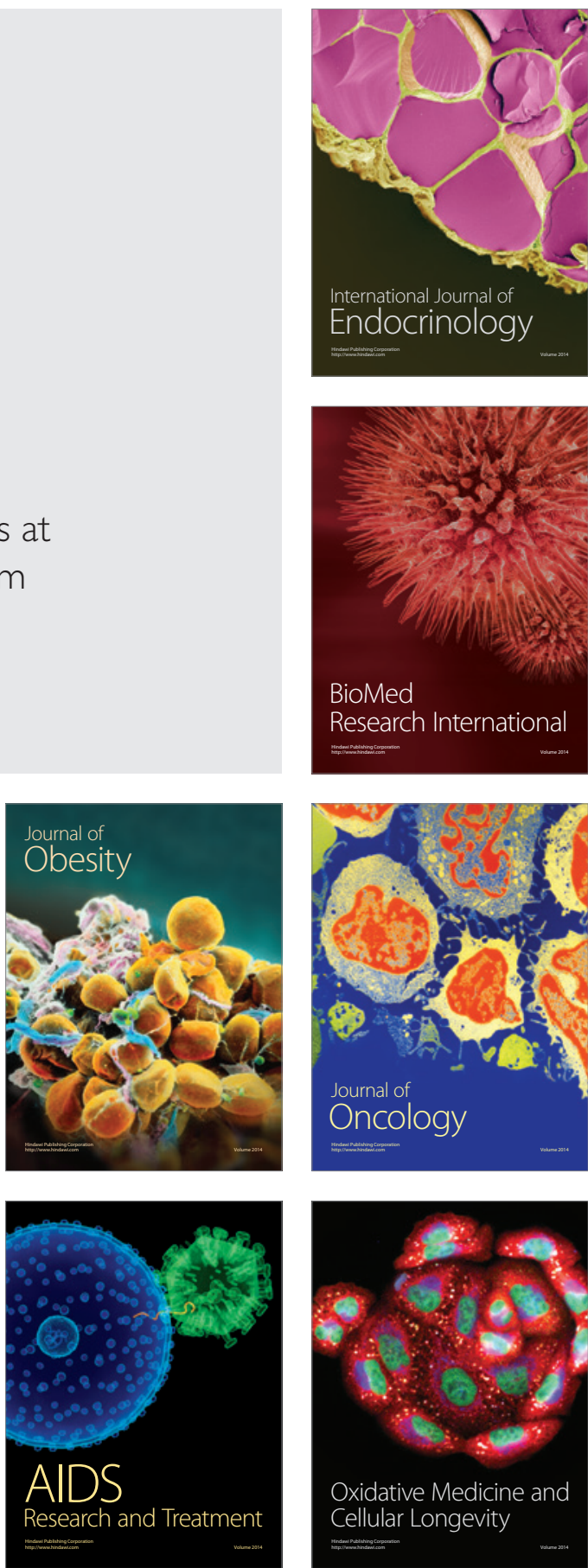